\title{
The Lipase-catalyzed Synthesis of Sugar Ester in Non- aqueous Medium
}

\author{
Yao Tingting \\ Key Laboratory for Food Science and Engineering \\ Harbin University of Commerce \\ Harbin, China \\ 657407999@qq.com
}

Li Quanhui

Key Laboratory for Food Science and Engineering Harbin University of Commerce

Harbin, China

1023281117@qq.com

\author{
Xin Jiaying* \\ Key Laboratory for Food Science and Engineering \\ Harbin University of Commerce \\ Harbin, China \\ xinjiayingvip@163.com \\ Corresponding Author
}

\author{
Gao Shengbo \\ Key Laboratory for Food Science and Engineering \\ Harbin University of Commerce \\ Harbin, China \\ 544546692@qq.com \\ Zheng Luoyun \\ Key Laboratory for Food Science and Engineering \\ Harbin University of Commerce \\ Harbin, China \\ 506637547@qq.com
}

\begin{abstract}
Sugar esters are nonionic surfactants. They are widely used in the food, cosmetic, detergent and pharmaceutical industry because of its high emulsifying capacity, non-toxicity, wide range of HLB value (1-16) and biodegradability. In addition, sugar esters have the effect of lubricating, detergency, foaming, anti-ageing, anticrystallizing and anti-bacteria etc. Sugar esters are recommended food additives by FAO and WHO. Enzymatic synthesis has many advantages over conventional chemical synthesis of sugar esters. It is very important to carry out the study of enzymatic synthesis of sugar ester in non-aqueous system. By the single factor experiments, the effects of reaction system, the content of sugar, the reaction temperature, the addition amount of lipase, the addition amount of molecular sieve and the reaction time on sugar ester transformation were investigated. On the basis of single factor experiments, the perpendicular experiments were designed to optimize the condition. The optimal conditions were built when the reaction was carried out in the tert-butyl alcohol with $0.6 \mathrm{~mol} / \mathrm{L}$ of lauric acid, $0.08 \mathrm{~mol} / \mathrm{L}$ of sucrose, $30 \mathrm{~g} / \mathrm{L}$ of lipase and $50 \mathrm{~g} / \mathrm{L}$ molecular sieves, at $50^{\circ} \mathrm{C}$ for 65 hours.
\end{abstract}

Keywords- sugar ester; lipase; enzymatic non-aqueous system

\section{INTRODUCTION}

Sugar esters represent a large group of compounds and consist of two abundant agricultural raw materials - sugars and fatty acids derived from fats or oils [1]. Sugar fatty acid esters can be synthesized from renewable resources such as fatty acids and carbohydrates. Sugar fatty acid esters have broad applications in the food industry [2]. Sugar fatty acid esters are nonionic surfactants [3] with attractive properties in a wide range of HLB values according to the different sugars and fatty acids used in the synthesis and are useful as industrial detergents and food emulsifiers [4]. In addition, their anti-tumoral and insecticidal properties have been reported [5]. Sugar fatty acid esters are safe to the human body and have very wide uses and flexibility. Sugar fatty acid esters are receiving more and more attention in the world [6]. Sucrose esters are the largest and most widely used sugar fatty acid esters in industrial production. Industrial produced sucrose esters are usually mixtures with different degrees of esterification. The degree of esterification is usually less than 4. Sugar fatty acid esters can be produced by non-enzymatic chemical routes. The chemical routes require more energy than that of the enzymatic route and have a low selectivity. In addition, the combination of high temperature and alkaline catalyst used in chemical processes can cause discoloration of the product and the formation of toxic byproducts. Some of the byproducts are allergenic and possibly carcinogenic [7]. Applications of commercial, chemically synthesized sorbitan and sucrose esters are limited because they are produced at high temperatures in toxic solvents which leave traces in the products; therefore a difficult and expensive purification is required. Chemical-synthesized products are often a mixture of mono-, di-and higher esters. Hence lipase-catalyzed synthesis is researched as an alternative [8]. The enzymatic synthesis of sugar esters has garnered considerable interest with regard to the creation of environment-friendly 
processes [9]. Enzymatic synthesis can be performed under mild reaction conditions, which can minimize side reactions and the browning of products. As the catalysts in organic synthesis, lipases not only catalyze hydrolysis but also esterification, transesterification and so on. Each lipase demonstrates its distinct substrate specificity, regioselectivity and steroselectivity. Enzyme-catalyzed reactions are superior to conventional chemical methods because of mild reaction conditions, high catalytic efficiency and the high selectivity. Further, use of immobilized enzyme can simplify the downstream processing [10]. The researchers have successfully synthesized a variety of fatty acid esters, including glucose esters, fructose esters, sucrose esters, maltose esters, mannitol esters, galactose esters etc. In this study, the reaction system for the synthesis of lauric acid sugar ester was established. The effects of the fatty acid concentration, the reaction solvent, the amount of sugar, the reaction temperature, the addition amount of lipase and 4A molecular sieve on the conversion of sugar esters are studied. The lipase-catalyzed synthesis of sugar esters under the non-aqueous system was optimized.

\section{MATERIALS AND METHODS}

\section{A. Selection of reaction system}

It was prepared at a concentration of $0.1,0.2,0.3,0.4$, $0.5,0.6,0.7,0.8,0.9$ and $1.0 \mathrm{~mol} / \mathrm{L}$ lauric acid solution of tert-amyl alcohol, lauric acid solution of tert-butanol and lauric acid solution of acetone respectively. $0.1 \mathrm{~mol} / \mathrm{L}$ sucrose, $20 \mathrm{~g} / \mathrm{L}$ Novozym435 lipase, $80 \mathrm{~g} / \mathrm{L}$ of $4 \mathrm{~A}$ molecular sieves were added into $5 \mathrm{~mL}$ of lauric acid solution. The reaction was carried at $45^{\circ} \mathrm{C}$ for $72 \mathrm{~h}$.

\section{B. Effect of sucrose addition amount}

$5 \mathrm{~mL}$ of $0.6 \mathrm{~mol} / \mathrm{L}$ lauric acid tert-butanol solution, was mixed with $0.02,0.04,0.06,0.08,0.1,0.12 \mathrm{~mol} / \mathrm{L}$ sucrose respectively. $20 \mathrm{~g} / \mathrm{L}$ Novozym 435 lipase, $80 \mathrm{~g} / \mathrm{L}$ of $4 \mathrm{~A}$ molecular sieves were added into $5 \mathrm{~mL}$ of lauric acid tert-butanol solution. The reaction was carried at $45{ }^{\circ} \mathrm{C}$ for $72 \mathrm{~h}$.

\section{Effect of reaction temperature}

$5 \mathrm{~mL}$ of $0.6 \mathrm{~mol} / \mathrm{L}$ lauric acid tert-butanol solution, $0.08 \mathrm{~mol} / \mathrm{L}$ sucrose, $20 \mathrm{~g} / \mathrm{L}$ Novozym 435 lipase, $80 \mathrm{~g} / \mathrm{L}$ of $4 \mathrm{~A}$ molecular sieves was added together and reaction was carried out at $35{ }^{\circ} \mathrm{C}, 45{ }^{\circ} \mathrm{C}, 55{ }^{\circ} \mathrm{C}, 65{ }^{\circ} \mathrm{C}, 75{ }^{\circ} \mathrm{C}$ respectively for $72 \mathrm{~h}$.

\section{Effect of the lipase addition amount}

$5 \mathrm{~mL}$ of $0.6 \mathrm{~mol} / \mathrm{L}$ lauric acid tert-butanol solution, $0.08 \mathrm{~mol} / \mathrm{L}$ sucrose $80 \mathrm{~g} / \mathrm{L} 4 \mathrm{~A}$ molecular sieves was added together and 10, 20, 30, 40, $50 \mathrm{~g} / \mathrm{L}$ Novozym435 lipase were added respectively at $55{ }^{\circ} \mathrm{C}$ to carry out the reaction for $72 \mathrm{~h}$.

\section{E. Effect of the molecular sieves addition amount}

$5 \mathrm{~mL}$ of $0.6 \mathrm{~mol} / \mathrm{L}$ lauric acid tert-butanol solution, $0.08 \mathrm{~mol} / \mathrm{L}$ sucrose, $30 \mathrm{~g} / \mathrm{L}$ of lipase Novozym 435 was added together and 20,40,60,80, $100 \mathrm{~g} / \mathrm{L}$ of molecular sieve were added respectively at $55{ }^{\circ} \mathrm{C}$ and reaction for 72 h.

\section{F. Effect of reaction time}

$5 \mathrm{~mL}$ of $0.6 \mathrm{~mol} / \mathrm{L}$ lauric acid tert-butanol solution, 0.08 $\mathrm{mol} / \mathrm{L}$ of sucrose, $30 \mathrm{~g} / \mathrm{L}$ of Novozym 435 lipase, $60 \mathrm{~g} / \mathrm{L}$ of $4 \mathrm{~A}$ molecular sieves were added together to begin the reaction at $55{ }^{\circ} \mathrm{C}$. The sugar ester conversion were measured at 12, 24, 36, 48, 60 and $72 \mathrm{~h}$. respectively

\section{RESULTS}

\section{A. Selection of reaction system}

As shown in Figure 1, when lauric acid concentration was varied from 0.1 to $0.3 \mathrm{~mol} / \mathrm{L}$ the sugar esters conversion was different in tert-amyl alcohol, t-butanol, and acetone. This may be due to the polarity and chemical properties of the solvent itself. When the lauric acid concentration is $0.6 \mathrm{~mol} / \mathrm{L}$, the reaction solvent is t-butanol, the highest conversion of sugar esters was reached to $78.4 \%$

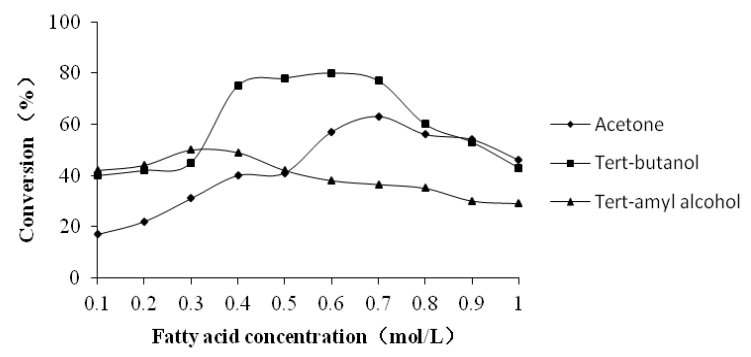

Figure 1. The effect of lauric acid concentration on the conversion

\section{B. Effect of sucrose addition amount}

Previous studies suggested that the ratio of sugar to fatty acid was an important factor that affects the reaction. This may attribute from the fact that only the part of the sugar dissolved into the reaction system, the amount of fatty acid in the reaction system is far greater than the amount of sugar in the reaction system. So the addition amount of sugar should be considered, which can improve the conversion of sugar ester. Figure 2 showed that when the amount of sugar was varied from 0.02 to $0.08 \mathrm{~mol} / \mathrm{L}$, sugar ester conversion was maintained at a high level. Considered to reduce the reaction volume and save solvent, the sucrose addition amount was chose at $0.08 \mathrm{~mol} / \mathrm{L}$.

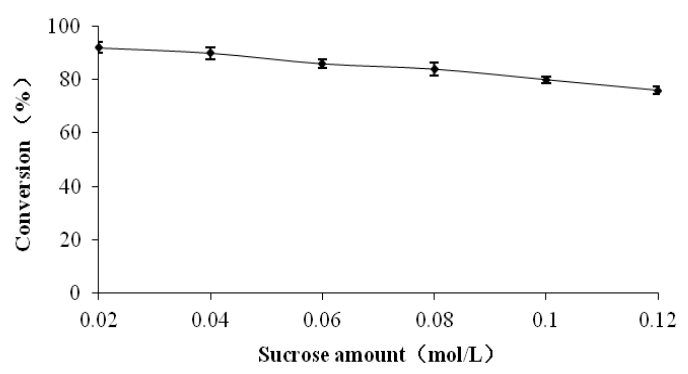

Figure 2. The effect of the concentration of sucrose on the conversion 


\section{Effect of reaction temperature}

The reaction temperature can affect the sugar ester synthesis reaction in many aspects, such as the reaction rate, the reaction equilibrium position, sugar solubility and enzyme activity etc. Novozym435 lipase is more heatresistant lipase. The effect of temperature on sugar esters conversion was investigated from $30{ }^{\circ} \mathrm{C}$ to $70{ }^{\circ} \mathrm{C}$. The elevated temperatures will not only increase the solubility of sucrose, but also affect the equilibrium of the reaction. As shown in Figure 3, when the temperature was gradually raised from $30{ }^{\circ} \mathrm{C}$ to $50{ }^{\circ} \mathrm{C}$, the sugar esters conversion gradually increased. The highest conversion was reached at $50{ }^{\circ} \mathrm{C}$.

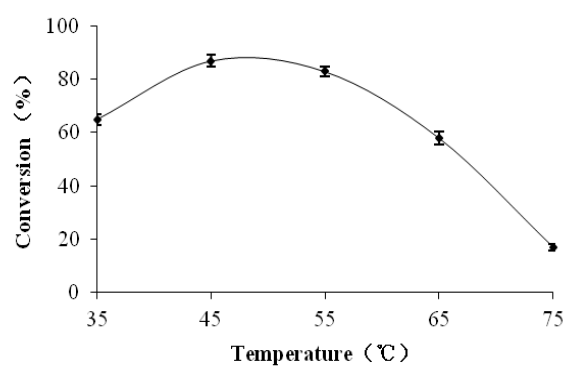

Figure 3. The effect of reaction temperture on the conversion

\section{Effect of the lipase addition amount}

Improved lipase addition amount in the reaction mixture can enhance the initial reaction rate and improve the conversion of sugar esters. However, lipase used in excess will result in high cost. Also, it is not conducive to mass transfer for the high addition amount of immobilized lipase. Figure 4 showed that when the addition amount of lipase was in the range of $10 \sim 20 \mathrm{~g} / \mathrm{L}$, the conversion of sugar esters gradually increased; when the addition amount of lipase was in the range of $20 \sim 30 \mathrm{~g} / \mathrm{L}$, the conversion of sugar esters was maintained in a relatively high level. So $30 \mathrm{~g} / \mathrm{L}$ was chose as the amount of lipase added.

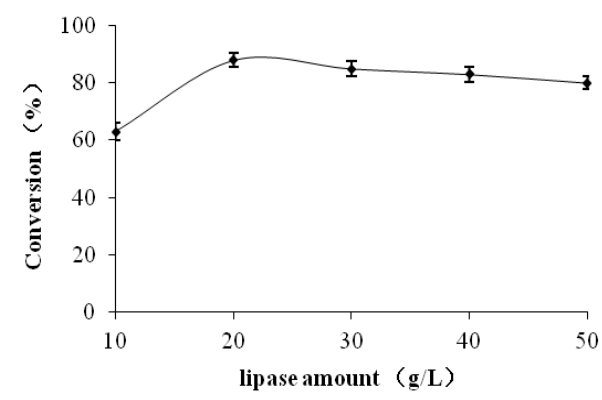

Figure 4. The effect of the lipase addition amount on the conversion

\section{E. Effect of the amount of molecular sieves added}

Water activity is an important factor that can affect the lipase-catalyzed synthesis of sugar esters non-aqueous system. Since water is a product of the esterification reaction, so as to carry out the reaction, the water activity of the reaction system are constantly changing. When water activity increase, the reverse reaction equilibrium will move, which result in the hydrolysis of sugar esters. In this reaction, the $4 \mathrm{~A}$ molecular sieves was added as waterabsorbing agent. The 4A molecular sieves can absorbed the water molecules produced in the sugar esters synthesis reaction catalyzed by lipase in non-aqueous system. It should be possible to reduce the water activity of the reaction system. Figure 5 showed that when the amount of molecular sieve added was in the range of $20 \sim 60 \mathrm{~g} / \mathrm{L}$, the conversion of sugar esters increased. When the amount of molecular sieve was in the range of $60 \sim 100 \mathrm{~g} / \mathrm{L}$, the conversion was stabilized. So $60 \mathrm{~g} / \mathrm{L}$ was chose as the addition amount of $4 \mathrm{~A}$ molecular sieves.

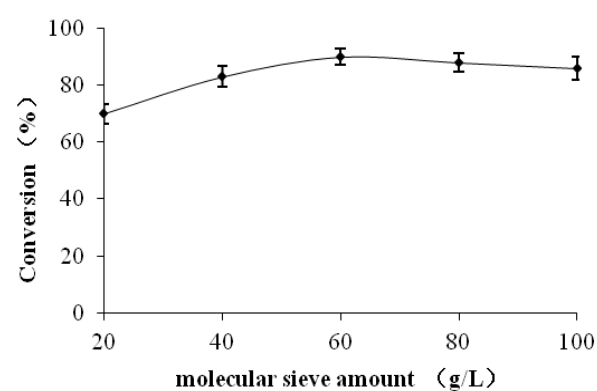

Figure 5. The effect of the amount of molecular sieves on conversion

\section{F. Effect of reaction time}

Figure 6 showed that the conversion of sugar esters was increased constantly with reaction time increasing, and tends to balance around $60 \mathrm{~h}$. As the reaction continues, the conversion of sugar esters also declined slightly. This may be attributed from the accumulation of the product in the solvent, molecular sieve saturated, and sugar ester hydrolysis. It can also be seen from the figure that the reaction rate decrease gradually with the increase of reaction time. This may be attributed from product accumulation.

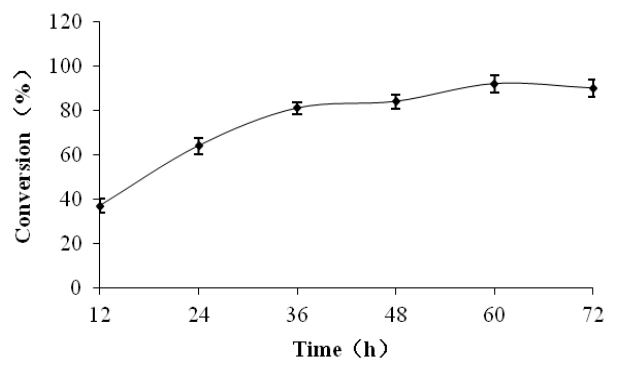

Figure 6. The effect of the reaction time on the conversion

\section{CONCLUSIONS}

In this paper, tert-butyl alcohol, tertiary amyl alcohol and acetone were used as reaction medium respectively. different concentration of lauric acid was used in the reaction system to synthesize lauric acid sucrose ester. The 
optimum reaction condition was established when the lauric acid concentration was $0.06 \mathrm{~mol} / \mathrm{L}$ with tertiary butyl alcohol as reaction system. Under this reaction system, the effect of the added amount of sugar, reaction temperature, the added amount of lipase, the added amount of molecular sieve, reaction time on the sugar ester conversion were studied. An optimum reaction process for the non-aqueous system lipase catalyzed synthesis of sucrose laurate was established. The reaction solvent is tbutanol; addition amount of lipase is $30 \mathrm{~g} / \mathrm{L}$; lauric acid concentration is $0.6 \mathrm{~mol} / \mathrm{L}$, sucrose concentration is 0.085 $\mathrm{g} / \mathrm{L}$; the reaction temperature is $50{ }^{\circ} \mathrm{C}$; reaction time is $65 \mathrm{~h}$, the addition amount of molecular sieve is $50 \mathrm{~g} / \mathrm{L}$.

\section{REFERENCES}

[1] YAN Y, BORNSCHEUER U T, STADLER G, et al. "Production of sugar fatty acid esters by enzymatic esterification in a stirredtank membrane reactor: optimization of parameters by response surface methodology, "Journal of the American Oil Chemists' Society, vol.78, Jan. 2001, pp. 147-153, doi: 10.1007/s11746-0010235-x.

[2] Ferrer M, Soliverib J, Ploua F J et al. "Synthesis of sugar esters in solvent mixtures by lipases from Thermomyces lanuginosus and Candida Antarctica B, and their antimicrobial properties," Enzyme and Microbial Technology, vol. 36, Mar. 2005, pp. 391-398, doi: 10.1016/j.enzmictec.2004.02.009.

[3] Ganske F, Bornscheuer U T. "Lipase-Catalyzed Glucose Fatty Acid Ester Synthesis in Ionic Liquids," Org. Lett., vol. 7, Aug. 2005, pp. 3097-3098, doi: 10.1021/o10511169.
[4] Cauglia F, Canepa P. "The enzymatic synthesis of glucosylmyristate as a reaction model for general considerations on 'sugar esters' production," Bioresource Technology, vol. 99, Jul. 2008, pp. 4065 - 4072, doi: 10.1016/j.biortech.2007.01.036.

[5] Ferrer M, Cruces M A, Plou F J, et al. "Chemical versus enzymatic catalysis for the regioselective synthesis of sucrose esters of fatty acids," Studies in Surface Science and Catalysis, vol.130, Jan 2000, pp. 509-514, doi: 10.1016/S0167-2991(00)81008-3.

[6] Liu X, Gong L, Xin M, et al. "The synthesis of sucrose ester and selection of its catalyst," Journal of Molecular Catalysis A: Chemical, vol. 147, Nov, 1999, pp. 37-40, doi: 10.1016/S13811169(99)00125-9.

[7] Gumel A M, Annuar M S M, Heidelberg T, et al. "Lipase mediated synthesis of sugar fatty acid esters," Process Biochemistry, vol. 46, Nov. 2011, pp. 2079-2090, doi: 10.1016/j.procbio.2011.07.021.

[8] Habulin M, Šabeder S, Knez. "Enzymatic synthesis of sugar fatty acid esters in organic solvent and in supercritical carbon dioxide and their antimicrobial activity," The Journal of Supercritical Fluids, vol. 45, Jul. 2008, pp. 338-345, doi: 10.1016/j.supflu.2008. 01.002 .

[9] Lee S H, Dang D T, Ha S H, et al. "Lipase-catalyzed synthesis of fatty acid sugar ester using extremely supersaturated sugar solution in ionic liquids," Biotechnology and Bioengineering, vol. 99, Jan. 2008, pp. 1-8, doi: 10.1002/bit.21534.

[10] Yu J, Zhang J, Zhao A et al. "Study of glucose ester synthesis by immobilized lipase from Candida sp," Catalysis Communications, vol.9, Mar. 2008, pp. 1369-1374, doi: 10.1016/j.catcom.2007.11. 036. 